\title{
Orienting ESL/EFL Students towards Critical Thinking through Pictorial Inferences and Elucidation: A Fruitful Pedagogic Approach
}

\author{
Vijay Singh Thakur ${ }^{1} \&$ Rahma Al-Mahrooqi ${ }^{2}$ \\ ${ }^{1}$ Department of Languages and Translation, College of Arts and Applied Sciences, Dhofar University, Oman \\ ${ }^{2}$ Department of English, College of Arts and Social Sciences, Sultan Qaboos University, Oman \\ Correspondence: Dr. Vijay Singh Thakur, Department of Languages and Translation, College of Arts and \\ Applied Sciences, Dhofar University, Oman. E-mail: vijay_oman@yahoo.co.in
}

\author{
Received: October 17, 2014 Accepted: November 27, 2014 Online Published: January 20, 2015 \\ doi:10.5539/elt.v8n2p126 URL: http://dx.doi.org/10.5539/elt.v8n2p126
}

\begin{abstract}
The notions of Critical Thinking (CT) and Lifelong Learning (LL) are mutually inseparable as both are required in every domain of one's educational and professional life in order to survive and flourish in today's world of increased literacy and competition. CT is an important functional skill, needed for students to analyze concepts and ideas to get a clear understanding of them. Review of a host of definitions of CT, included in this paper, suggests that it basically involves a plethora of thinking abilities for the purposes of evaluating one's own thinking process that results in a meaningful learning experience. However, unlike ordinary thinking, which is an inborn human ability, CT needs to be inculcated through implicit and/or explicit instruction. Many researchers (e.g. Benesch, 1993; Atkinson, 1997; Oster, 1989; Brookfield, 1987; Shor \& Freire, 1987; Fox, 1994; etc.) explain CT as a means to transform learning and society and they believe that social practice is one of the indispensable components of CT. In view of this, we need to orient our ESL / EFL students towards CT, along with the teaching of language skills, through interactive instructional practices. Considering the role(s) CT can play in developing information-based societies and the pedagogical gains that can be made through the use of visuals in teaching language skills and $\mathrm{CT}$, this paper aims to discuss and demonstrate how certain schematic pictorial presentations can be exploited as stimuli to orient ESL / EFL learners towards CT. The significance of this paper also lies in encouraging researches which explicitly link CT with pictorial presentations of cartoons and caricatures.
\end{abstract}

Keywords: critical thinking, knowledge-based societies, lateral thinking skills, interactive instructional practices, pictorial inferences and elucidation

\section{Introduction}

The necessity to develop a knowledge-based society has been emphasized as a global challenge in the Geneva World Summit on Information Society (2003, cited in Vezzosi, n.d.) with a call for collective commitment of nations to build:

[...] a people-centred, inclusive and development-oriented Information Society, where everyone can create, access, utilize and share information and knowledge, enabling individuals, communities and peoples to achieve their full potential in promoting their sustainable development and improving their quality of life (p. 1).

CT is crucial to achieve this ambitious mission. In view of Chaffee's (1995) line of argument, enhancing students' CT abilities is the core of meaningful education. The main goal of education is not only to help people share information and knowledge but also, more importantly, to help people make a personal contribution to public life, which requires a due level of competence in CT. This leads to orienting our ESL / EFL learners towards training in CT.

Incidentally, according to cognitive semantic studies (e.g. Paivio, 1971; Clark \& Paivio, 1991), dual coding of input, i.e. both verbal and visual, promotes the formation of memory traces and the retention of information. The findings of these studies have prompted the use of mental imagery in language teaching, where pictorial inferences and elucidation have been found to improve comprehension. It has been discovered that information that is presented through both visual and verbal modes is stored and retrieved more easily than information presented through one modality alone. 
In view of the importance of $\mathrm{CT}$ and the benefits of a dual coding mechanism involved in visual teaching, this paper demonstrates how language learners can be oriented towards CT in ESL/EFL classrooms through the use of one of the best visual aids, i.e. cartoons, and recommends that this neglected resource of schematic pictorial presentations be exploited for promoting CT through ESL / EFL classrooms.

Before getting down to discuss how cartoons can be used for orienting our students towards $\mathrm{CT}$, it is necessary to examine $\mathrm{CT}$ in its definitional and theoretical perspectives.

\section{What Is CT?}

The pedagogical concept of CT is rooted in the Socratic notion of "deep questioning", which manifests in almost all the definitions of CT. Norris and Ennis (1989) define CT as "reasonable reflective thinking" focused on deciding what to believe or do through cognitive skills of analyzing, inferring, interpreting, and evaluating (p. 3). Thus, having qualities of 'explanation' and 'self-regulation', CT allows individuals to strengthen their own powers of ratiocination and lateral thinking skills. Lipman (1991) defines it as "healthy skepticism". Lewis \& Smith (2001) call it "higher order thinking", while Jacobson and Ignacio (1997) and Jacobson (1998) consider it to be "conscious use of learning strategies", which involves engagement in a task and increases the awareness of the context. According to Jacobson (1998), CT entails self-improvement, which corresponds with the findings of Varadani \& Mehrali's (2013) study in that there is a significant relationship between CT and self-efficacy and levels of proficiency (p. 2355). Halpern (1996) considers CT as "goal-directed" and "evaluation-oriented". A similar definition is provided in Whitmore's (1998) analysis which looks at CT as an ability to identify central issues, evaluate conflicting claims based on evidence on authority, and interpret whether conclusions are warranted or not accordingly (pp. 266-273). Siegel (1988) highlights two elements of CT that are relevant to educational contexts, namely (a) the ability to assess reasons adequately, and (b) the critical attitude reflected in the willingness, desire and disposition to support one's beliefs and actions by reasons (p. 23). Lakshmi (2012) is of the view that, in the context of classroom teaching, any conscious thinking that is goal-oriented is CT (p. 113). Put precisely, all the thinking abilities, as reflected in the above definitions, can be broadly put under the three sub-skills of CT, namely creative thinking, logical reasoning, and problem solving.

After looking at $\mathrm{CT}$ in its definitional perspective, it is now time to highlight its theoretical foundations.

\section{Theoretical Foundations of CT}

CT has strong theoretical foundations and scaffoldings to base on and erect as a fruitful pedagogical practice in ESL / EFL classrooms. Bloom (1981) developed a system, popularly known as Bloom's Taxonomy, of classifying levels of thinking in the cognitive domain involved in the learning process. The thinking in cognitive domain builds on the simple factual knowledge at the lowest level whereas evaluation at the highest level. Piaget \& Inhelder's (1970, cited in Vezzosi, n. d., p. 7), consider thinking skills as maturational, which bring individuals to consider their lives from the point of view(s) of others in order to think and evaluate their own thinking. Vygotsky's model (2000, cited in Vezzosi, n. d., p. 7) proposes that thinking and its constructs are products of social and interpersonal activity, which eventually get internalized as individual knowledge. Benesch's (1993) model emphasizes CT as a social practice and examines it as a quest for social, political and historical roots of traditional knowledge and also as an orientation to transform learning and the society.

With a section on the theoretical foundations of CT, what follows next is a discussion on why and how pictorial presentations of cartoons and caricatures can be effective means of facilitating orientation of CT in ESL/EFL classrooms.

\section{Why use cartoons for developing CT through language teaching?}

It is significant to mark the way learning takes place. An American study reports that the maximum 83 per cent learning takes place by seeing and only 17 per cent by other senses of tasting, touching, smelling, and hearing put together (cited in Thakur, 2004, p. 38). Thus, visuals seem to play a great role in learning. Keeping this in mind, visual teaching needs to be explored and thoroughly exploited for effective learning.

By common consensus, pictures are the best visual aid. A Chinese maxim, highlighting this fact, says that one picture is better than a thousand words. Every picture tells a story and children are visual by nature. Given the choice of an editorial cartoon and a newspaper article to pick up from, the children would go for the cartoon. As Wright and Sherman (2006) argue (cited in Rahim, Abdul Halim \& Mamat, 2014, p. 8) cartoons have particular attention among school-age children. The impact of cartoons is spontaneous and, irrespective of age and background, to use VanWyk's (2011) remark, learners are found to respond in some way or the other in the classroom (p. 117). Put precisely, as Rahim, Abdul Halim and Mamat (2014) rightly argue, cartoons are particularly useful because they are stimulating, varied, and often humorous. And, moreover, they are also a 
major attraction toward learners in a difficult learning situation (p. 9). So, in view of so many motivating reasons, why not exploit the qualities of cartoons that are suitable for language teaching and training in CT in our ESL/ EFL classrooms?

Cartoons, to use Rahim, Abdul Halim and Mamat's (2014) remark, have been a favorite for people of all ages (p. 8). In order to link the potential and fertility of cartoons and caricatures with CT, we would like to bring in here Brookfield (1987), and Shor and Freire's (1987) research in which they endorse Benesch's (1993) view on CT being a quest for the social, historical, and political roots of conventional knowledge and an orientation to transform learning and society (cited in Rezaei, Derakhshan, \& Bagherkazemi, 2011, p. 771). Incidentally, the format of cartoons and caricatures often produces a strong political, economic, and social impact. Editorial cartoons cover a variety of high-level concepts that are hard to convey in written texts. Language does not prove to be a barrier in dealing with visual presentations. Thus, cartoons and caricatures can be a rich and viable resource for a variety of purposes in language teaching and promoting CT.

In addition, there are several other qualities for which cartoons can be used for promoting $\mathrm{CT}$ in language teaching. They have a broad coverage of international affairs such as population, pollution, love, adventure, war, corruption, nepotism, favoritism, scandals, personal and social life, etc., which evoke readers' general knowledge and inteest. They are easy to understand and their originality, freshness, unusualness, and spontaneity delight and refresh their readers. They provide realistic, truthful, authentic, and relevant information in a revealing manner and the information is presented both indirectly and in a context. Often there may also be an opinion gap-i.e. the reader and the cartoonist may not agree on a certain issue-which leaves purposeful scope for readers to express their opinions. Patil (1996) calls it the cartoonist's vantage point (p. 17). For these qualities we strongly recommend cartoons and caricatures as a suitable teaching material to orient language learners towards CT and also suggest this genre of humour and satire for pedagogical research.

We can now move on to demonstrating how pictorial presentations of cartoons and caricatures can be fruitfully exploited to orient ESL / EFL students' language learning towards CT.

How to use cartoons in language teaching?

Cartoons are very suitable for pair and group work. They can be used for brainstorming and negotiation. While working in a pair or group, students have to put their heads together to relate the cartoon to its social or political context and then negotiate the cartoon's meaning and message in consultation with each other. This activates their shared knowledge and experience of the world. As Patil (1996) suggests, the students may be made to discuss the semantic, pragmatic, and sociolinguistic meanings of a cartoon and share their interpretations with the class (p. 17). Cartoons can also be used for written composition and interdisciplinary thinking. When a group works on a cartoon, they read it and also listen to others' opinions and ideas. When group leaders report a collective interpretation to the class, they speak and others listen. When groups write their composition on a cartoon, they make use of others' ideas gathered from the discussion. Thus, the use of cartoons promotes collaborative-cooperative learning and facilitates integration of the four skills of reading, speaking, listening, writing, and also CT skills.

Cartoons can also be helpful in many other ways. For example, they can be used to develop and test students' ability to read between and even beyond the lines. Like literature, cartoons make special use of language. Their captions are hyper-semanticized, which could be used for enriching students' language. They can be taught how much meaning can be packed into a small presentation. Through cartoons we can teach our students ways of saying the unsayable effectively. They can also be used to show how to be indirect in order to sensitize students to ways of being euphemistic. We can teach them how meanings are context-bound and context-sensitive. We can also show them how a tragic event might have a comic lining and vice-versa. By using cartoons, past and present happenings (for example elections) may be taught. And, being value-oriented, we can use them for value education too.

Above all, teaching through cartoons can enliven classes, especially when they become monotonous and dull and students then feel uninterested and bored with learning. Through cartoons they can have fun and relaxation. As Smith (1993) rightly remarks, there will be something in every cartoon to please even the most cynical student at the back of the class (p. 58).

The possibilities and scope for the use of cartoons and caricatures in teaching English and developing CT are inexhaustible. Let us explore some of them. 


\section{Some CT Tasks and Activities Based on Cartoons and Caricatures}

Thinking is crucial to learning a language. Kabilan (2000, cited in Dugar, 2012) rightly argues that teaching students 'how to think' rather than 'what to think' is a way of recognizing their individuality and their potential for thinking and learning on their own and demanding accountability from them and thereby motivating them to learn the application of their knowledge (p. 105). The following tasks and activities, aiming at orienting ESL/ EFL students towards "how to think", are based on the six thinking dispositions developed through the Project Zero of Harvard University on the concept of 'Artful Thinking'. Incidentally, Artful Thinking Program provides learners with the techniques of 'deep thinking' (cf. Socratic notion of "deep questioning") and exploits the force of art for developing learners' CT. The six thinking dispositions of exploring viewpoints, reasoning, questioning and investigating, observing and describing, comparing and connecting, and finding complexity (pp. 8-9), as suggested by Tishman and Palmer (2006), are targeted in the artful thinking project. Incidentally, we have also suggested, in this paper, ways and means of exploiting the above dispositions in order to develop and promote CT skills in ESL / EFL classrooms through the use of satirical art of cartoons and caricatures. The following section demonstrates as to how this art can be fruitfully used for orienting students towards CT in ESL/EFL classrooms.

The tasks and activities suggested on the following cartoons, as a prototype format, involve brainstorming, reflection, discussion, debate, etc through a pair and / or group activity, followed by individual and / or pair and group writing and editing, and presentation.

1) The following humorous cartoon / caricature can be used for simple / light critical thinking.

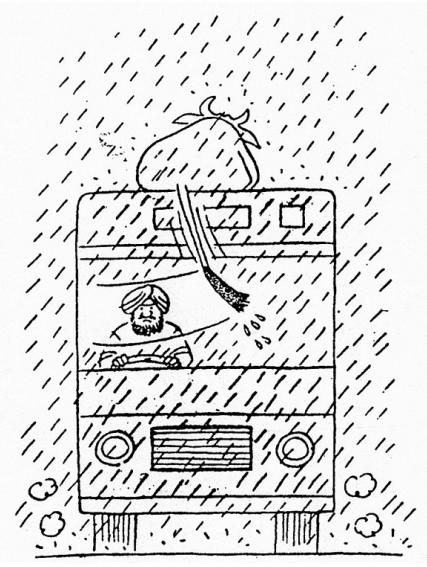

Figure 1. Cartoon (Abraham, 1988)

Examine the cartoon in Figure 1 and answer the following questions. Give reason(s) and explain your point(s) of view. If you don't agree with others' views, present your counter arguments.

- Is the driver in the above picture stupid or intelligent? Why do you think so?

- What is the purpose of this cartoon?

- Is there any important idea or message that the cartoonist wants to convey to the readers?

- Could that idea or message be explained, with the same effect, verbally or through any other mode?

- How useful could the message be in our life?

2) The following pair of caricatures in Figure 2 can be exploited for discussion through a serious contrastive approach to CT. 

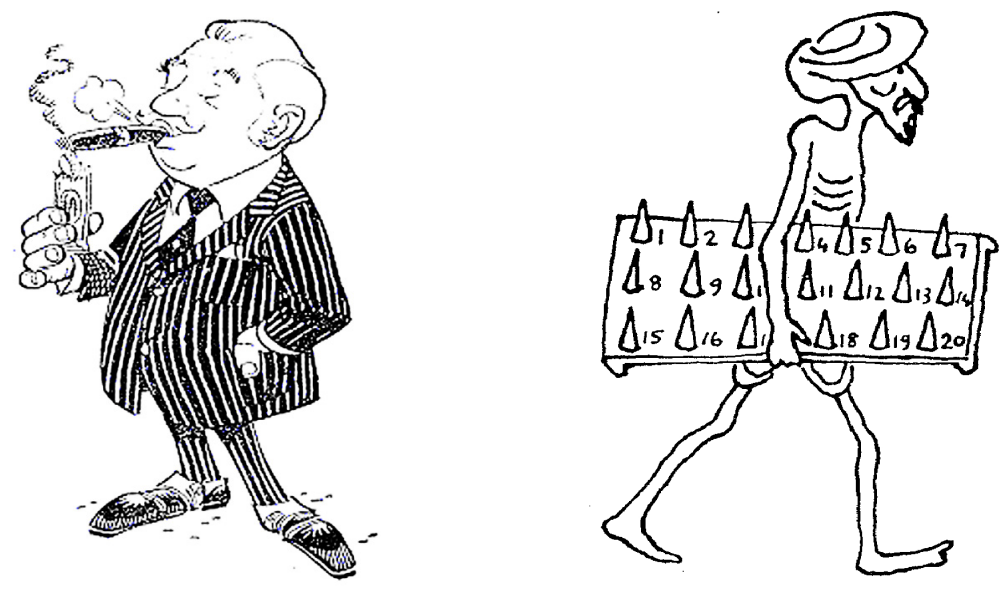

Figure 2. Caricatures (Curry, 1994; Abraham, 1988)

Examine the above pictures and reflect upon the following:

- Who are the characters in the two pictures?

- Do they represent a particular section or class from a social point of view?

- Can you comment upon their life and social status?

- What is the significance of the 'dollar' and the 'plank with a date-wise numbered nails' in the two caricatures of Figure 2? Can the 'dollar' and 'numbered nails' be associated with the situation of life of the people in the two pictures? How? Discuss.

- Can you read any social or political message in the two pictures?

- Who is responsible, from a comparative socio-political point of view, for the disparity reflected in the two pictures?

- Can this disparity be minimized and eventually equalized? If yes, how; If not, why?

3) The next two cartoons, i.e. in Figure 3, are very suitable for teaching higher-order critical reading between and beyond the lines. The unexpected contrast present in the two cartoons can be used to activate the readers' sensitivity, awareness, and concern about the issues brought up in them. Both cartoons are packed with meaning. The issues of 'poverty and homelessness' and 'the arms race' have been raised by contrasting animals and human beings in the first picture of Figure 3, in terms of their respective living conditions and by aliens from another planet identifying earth with the help of piles of missiles accumulated by human beings in the second picture of Figure 3. As the presentations are highly suggestive in nature and powerful in the themes, they offer lot of scope for the readers to express their ideas and arguments. We can use such cartoons for group work, ask the students to discuss and record their observations and reflections, and write a detailed analysis.
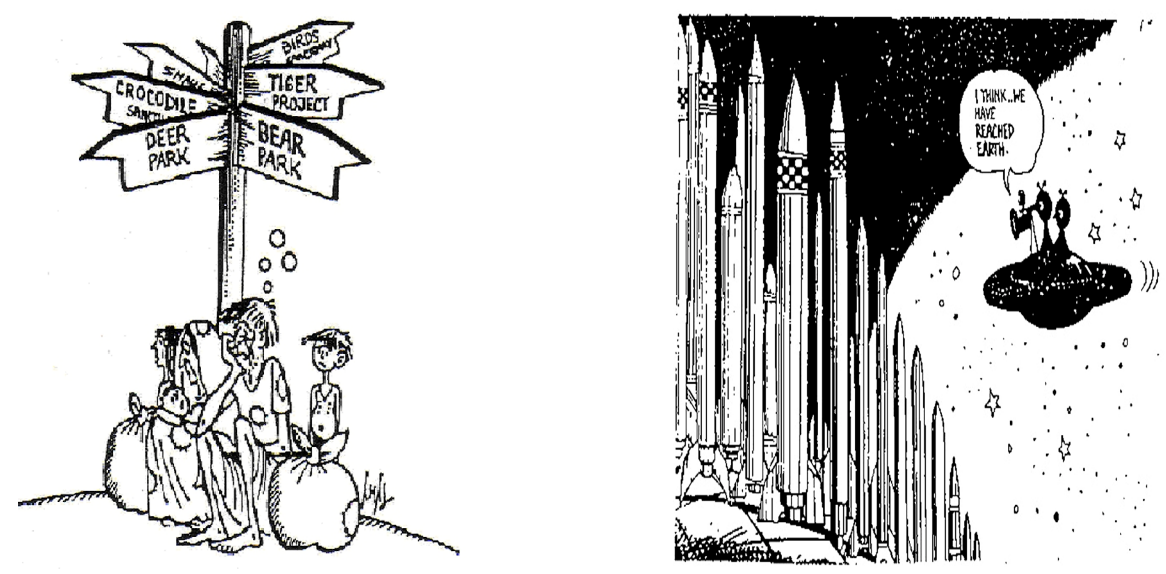

Figure 3. Cartoons (Abraham, 1988) 
The following task may be given:

Analyze the two cartoons. Your discussion should answer / address the following questions.

- What is the central idea of the two cartoons?

- Is the idea presented in each picture in an effective manner?

- Are the ideas presented in the two cartoons highly exaggerated, i.e. they are far from the reality? Why do you think so?

- How would you react to the two situations from a socio-political angle?

- What is implied / suggested about the people and the government(s) in each cartoon?

- How can the same idea be presented differently, i.e. by using other situations?

- How can the situation be changed for the better? Discuss.

4) And finally, here is a set of two more serious pictorial presentations for critical examination and reflection on the cartoonist's point of view:
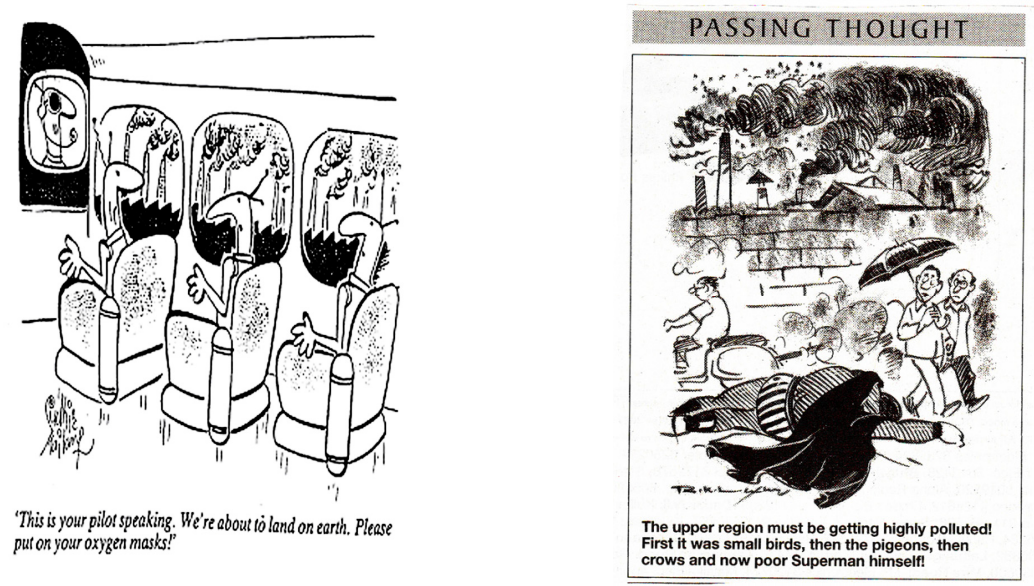

Figure 4. Cartoons (Abraham, 1988; Laxman, 2002)

We can ask the students to work in groups, discuss and build opinions / arguments / points of view and present them to the rest of the class.

- Study the point of view adopted by the two cartoonists in their pictorial presentations.

- Point out the humorous as well as serious aspects of the cartoons.

- How much is true and how much exaggerated in the two pictures? Justify your claims by giving effective reasons.

- Is the exaggeration justified? If so, how? If not, why?

- Which cartoon, in your opinion, projects the problem more effectively? Why do you think so? Discuss.

- Is it possible / impossible to control the problem projected in the two cartoons? In either case, discuss how.

The list, of course, is not exhaustive. Many more powerful cartoons could be explored, identified and selected, and many more innovative tasks and activities that could orient ESL/EFL learners towards CT could be built on them.

\section{Conclusions}

Students' natural attraction towards visuals can be thoroughly exploited and the gains of visual teaching may be considerably maximized through the use of cartoons in ESL/EFL classrooms. As cartoons and caricatures are an inexhaustible resource of humor and fun, learners will enjoy working on them, and their use will ensure better learner motivation and participation. An innovative and resourceful teacher can thus yield meaningful results not only in developing students' language skills but also in promoting their higher-order critical, lateral, and reflective thinking skills. With the help of carefully selected satirical pictorial presentations, every aspect of language can be taught and students can be fruitfully oriented towards CT in terms of enhancing a set of 
higher-order thinking skills and raising their awareness for social change. Hence, it is suggested and recommended that a carefully selected set of good cartoons and caricatures, along with learner-friendly stimulating tasks and activities on them, should be included in the curriculum for language teaching in general and for orienting learners towards CT in particular. In this way, learners can grow, excel and contribute as responsible critical thinkers within today's information-based world of technological advancement and increased competition. The authors therefore strongly implicate educators in considering the use of cartoons and caricatures for teaching CT in ESL / EFL classrooms. As no studies have been conducted on examining the explicit relationship between cartoons and critical thinking we highly recommend that the researchers explore, examine and investigate the potential and potentialities of this neglected and fertile area of pedagogical research.

\section{References}

Abraham, A. (1988). The Penguin book of Indian cartoons. New Delhi: Penguin Books.

Atkinson, D. (1997). A critical approach to critical thinking in TESOL. TESOL Quarterly, 31(1), 75-79.

Benesch, S. (1993). Critical thinking: A learning process for democracy. TESOL Quarterly, 31(3), 545-547.

Bloom, B. S. (1981). All our children learning: A primer for parents, teachers, and other educators. New York: McGraw-Hill.

Brookfield, S. (1987). Developing critical thinkers. Milton Keyes: Open University Press.

Chafee, J. (1985). Thinking critically. Boston: Houghton Miftlin Company.

Clark, J. M., \& Paivio, A. (1991). Dual coding theory and education. Educational Psychology Review, 3, $233-262$.

Curry, D. (1982). Illustrated American idioms. Washington D.C.: The Materials Branch, English Language Programs Division, United States Information Agency.

Dugar, P. C. (2012). The role of critical and creative thinking in the TESL context. In Z. N. Patil (Ed.), Innovations in English Language Teaching: Voices from the Indian Classroom (pp. 101-112), Hyderabad: Orient Blackswan.

Fox, H. (1994). Listening to the world: Cultural issues in academic writing. Urbana, IL: National Council of Teachers of English.

Halpern, D. (1996). Thought and knowledge: An introduction to critical thinking. Mahwah: Lawrence Erlbaum.

Jacobson, F. F. (1998). Teachers improving learning using metacognition with self-monitoring learning strategies. Education, 118(4), 579-589.

Jacobson, F. F., \& Ignacio, E. (1997). Teaching reflection: Information seeking and evaluation in a digital library environment. Library Trends, 45, 771-802.

Kabilan, M. K. (2000). Creative and critical thinking in language classrooms. The Internet TESL Journal, 6(6). Retrieved from http://iteslj.org/Techniques/Kabilan-CriticalThinking.html

Laxman, R. K. (2002). Passing thought. In The Times of India of 13 October.

Lakshmi, G. S. (2012). Techniques of teaching critical thinking. In Z. N. Patil (Ed.), Innovations in English Language Teaching: Voices from the Indian Classroom (pp. 113-133). Hyderabad: Orient Blackswan.

Lewis, \& Smith. (2001). Defining higher order thinking. Theory into practice, 32(3), 131-137.

Lipman, M. (1991). Thinking in education. Cambridge: Cambridge University Press.

Norris, S. P., \& Ennis, R. H. (1989). Evaluating critical thinking. Pacific Grove, CA: Midwest Publications.

Oster, J. (1989). Seeing with different eyes: Another view of literature in ESL class. TESOL Quarterly, 23(1), $85-103$.

Patil, Z. N. (1996). Using cartoons in the Teaching of English. Journal of English and Foreign Languages, 17, $15-26$.

Paivio, A. (1971). Imagery and verbal processes. New York: Rinehart \& Winston.

Piaget, J., \& Inhelder, B. (1970). La psicologia del bambino. Torino: Einaudi.

Rahim, N. A., Halim, H. A., \& Mamat, R. (2014). Learning via television cartoon. Asian Social Science, 10(15), 8-15. http://dx.doi.org/10.5539/ass.v10n 15p8 
Rezaei, S., Derakhshan, A., \& Bagherkazemi, M. (2011). Critical thinking in language education. Journal of Language Teaching and Research, 2(4), 769-777. http://dx.doi.org/10.4304/j1tr.2.4.

Shor, I., \& Freire, P. (1987). A pedagogy for liberation: Dialogues on transforming education. New York: Routledge \& Metheun.

Siegel, H. (1988). Educating reason: Rationality, critical thinking and education. New York: Routledge and Metheun.

Smith, J. (1993). Cartoons in the Class. Practical English Teaching. June, 58-59.

Thakur, V. S. (2004). Teaching English through cartoons and caricatures: A Viable approach. In V. V. Vincent (Ed.), Muscat Message (pp. 38-45), Sultanate of Oman: Ministry of Education.

Tishman, S., \& Palmer, P. (2006). Artful thinking. Cambridge, MA: Harvard Graduate School of Education.

VanWyk, M. M. (2011). The use of cartoons as a teaching tool to enhance student learning in Economics education. Journal of Social Science, 26(2), 117-130.

Vardani, S. B., \& Mehrali, S. (2013). Investigating the effect of levels of proficiency on Iranian male and female EFL learners' critical thinking and self-efficacy. Theory and Practice in Language Studies, 3(12), 2355-2361.

Vezzosi, M. (n.d.). Critical thinking and reflective practice: The role of information literacy.

Vygotsky, L. S. (2000). Pensiero e linguaggio: Ricerche psicologiche. Roma: Laterza.

Whitmore, E. (1998). Development of critical thinking skills: An analysis of academic library experiences and other measures. College and Research Libraries, 59(3), 266-273.

World Summit on the Information Society. (2003). Building the information society: A global challenge in the new millennium. Declaration of principles. Retrieved from http://www.itu.int/dms_pub/itu-s/md/03/wsis/ doc/S03-WSIS-DOC-004!!PDF_E.pdf

\section{Copyrights}

Copyright for this article is retained by the author(s), with first publication rights granted to the journal.

This is an open-access article distributed under the terms and conditions of the Creative Commons Attribution license (http://creativecommons.org/licenses/by/3.0/). 